\title{
Cardiovascular safety of antihistamines
}

\author{
Anna Olasińska-Wiśniewska ${ }^{1}$, Jerzy Olasiński², Stefan Grajek $^{1}$ \\ ${ }^{1} 1^{\text {st }}$ Department of Cardiology, Poznan University of Medical Sciences, Poznan, Poland \\ Head of Department: Prof. Stefan Grajek MD, PhD \\ ${ }^{2}$ Department of Dermatology, Poznan University of Medical Sciences, Poznan, Poland \\ Head of Department: Prof. Zbigniew Adamski MD, PhD
}

Postep Derm Alergol 2014; XXXI, 3: 182-186

DOI: $10.5114 /$ pdia.2014.43191

\begin{abstract}
Histamine is a mediator, which increases the permeability of capillaries during the early phase of allergic reaction, causes smooth muscle contraction of bronchi and stimulates mucous glands in the nasal cavity. Antihistamines are the basis of symptomatic treatment in the majority of allergic diseases, especially allergic rhinitis, allergic conjunctivitis, urticaria and anaphylaxis. The cardiotoxic effects of the two withdrawn drugs, terfenadine and astemizole, were manifested by prolonged QT intervals and triggering torsades de pointes (TdP) caused by blockade of the 'rapid' $I_{K r}$ potassium channels. These phenomena, however, are not a class effect. This review deals with a new generation of antihistamine drugs in the context of QT interval prolongation risk.
\end{abstract}

Key words: histamine, $\mathrm{H} 1$ receptor, antihistamines, $\mathrm{QT}$ interval, torsades de pointes.

Histamine is a mediator abundantly released by mast cells. It covers a broad spectrum of biological activities executed through the pathways of $\mathrm{H} 1, \mathrm{H} 2, \mathrm{H} 3$ (present mainly in the nervous tissues), and $\mathrm{H} 4$ receptors, as well as through the intracellular Hic receptor [1, 2]. The symptoms of allergic response are a result of histamine acting on $\mathrm{H} 1$ receptors. In the early IgE-dependent allergic reaction, along with other mediators, histamine increases general permeability of capillaries and arterioles and permeability of vessels to plasma proteins. It causes smooth muscle contraction of bronchi and stimulates mucous glands in the nasal cavity [2]. The mediators of allergic response are virtually the same in different tissues, yet clinical symptoms are specific to particular organs. Skin develops hives and erythema, lower respiratory tracts induce bronchoconstriction, dyspnea, wheezing and coughing, while nasal mucous membranes respond through pruritus, sneezing, production of aqueous secretion and nasal congestion. Stimulation of $\mathrm{H} 1$ receptors within the cardiovascular system results in the constriction of coronary blood vessels and induces a positive chronotropic effect, while the stimulation of $\mathrm{H} 3$ receptors is negatively chronotropic [3]. Additionally, histamine may inhibit $\beta 1$-adrenergic receptors within the heart muscle.

Antihistamines are the logical basis of symptomatic treatment in the majority of allergic diseases, especially allergic rhinitis, allergic conjunctivitis, urticaria and ana- phylaxis. They act on a receptor level by competing for $\mathrm{H} 1$ receptor sites with histamine (competitive antagonism). Once bonded to inactive receptors, they stabilize them in their inactive form, thus preventing activation by their natural agonist - histamine (inverse agonism) [1]. On top of that, antihistamines show anti-inflammatory and anti-allergic action that is not receptor related, e.g. through the inhibition of mast cell degranulation, eosinophil and neutrophil chemotaxis and down-regulation of nuclear factor $\kappa \mathrm{B}(\mathrm{NF} \kappa \mathrm{B})$ activity [1]. Novel antihistamine drugs, such as rupatadine, additionally block the platelet-activating factor (PAF) receptor, which plays an important role in allergic response, by inducing bronchoconstriction and bronchial hyperresponsiveness, increased permeability of vessels and neutrophil chemotaxis [1, 4]. Early antihistamines (first-generation - Table 1), introduced in the 1940s, affect also dopaminergic, serotonergic and cholinergic receptors, inducing multiple side-effects, such as sedation. The advantage of newer antihistamines (second - and third-generation) is the selective $\mathrm{H} 1$ binding and their anti-inflammatory effect. The newest third-generation antihistamines are either metabolites or isomers of the second-generation drugs (Table 1).

A certain level of concern regarding the safety of antihistamines was brought up by cardiotoxic effects of the first two second-generation antihistamines - terfenadine and astemizole. These effects were primarily manifested

Address for correspondence: Anna Olasińska-Wiśniewska MD, PhD, Department of Cardiology, Poznan University of Medical Sciences, 1/2 Długa St, 61-848 Poznan, Poland, phone: +48 603862 713, fax: +48 6166185 28, e-mail: anna.olasinska@poczta.onet.pl Received: 19.01.2014, accepted: 25.03.2014. 
by the appearance of the acquired, drug-induced long QT syndrome (LQTS). This phenomenon is caused by blockade of the 'rapid' I $I_{k r}$ potassium channel, encoded by the human Ether-à-go-go-Related Gene (hERG) [5, 6]. The channel is activated during phase 3 of the action potential - repolarization. Action potential is prolonged, once the channels are blocked. In such event, surface electrocardiogram (ECG) displays long QT intervals, while the patient is more vulnerable to the particularly threatening torsades de pointes that might develop into ventricular fibrillation and eventually death. Potassium channel blockade most likely results from the characteristic structural properties of particular drugs and their polarity $[3,5]$.

The assessment of QT interval prolongation is usually straightforward and requires a surface electrocardiogram (ECG) - Table 2. Notably, drug-induced prolongation of QT interval may be detected during treatment with the use of control electrocardiograms.

The first case of torsades de pointes, regarding a 16-year-old female and resulting from an ingestion of 20 astemizole tablets (200 mg), which had been prescribed $10 \mathrm{mg}$ daily due to allergic rhinitis, was presented by Craft in 1986 [7]. A similar case of terfenadine overdose in a 21-year-old female was described by Davies et al. in 1989 [8]. Other case studies, concerning cardiotoxic side-effects of overdosed astemizole or terfenadine, followed shortly after $[9,10]$.

As a result of these disturbing data, having carefully analyzed over 20 cases of fainting, ventricular tachycardia, torsades de pointes and cardiac arrests that followed administration of astemizole or terfenadine, the Food and Drug Administration (FDA) published a warning for physicians describing the conditions of usage of these medicines [9]. It was established that torsades de pointes might appear not only in cases of overdose [11], but also in the presence of other factors up-regulating the concentration of these drugs in the serum. Most of such cases were related to astemizole or terfenadine metabolism disorders. Some antihistamines, e.g. terfenadine, astemizole, levocetirizine or rupatadine are metabolized in the liver by the cytochrome P450 enzyme complex - the CYP3A4 isoenzyme, while loratadine is also metabolized by the CYP2D6 isoenzyme [3]. Certain metabolites, e.g. cetirizine, desloratadine and bilastine, are not metabolized in the liver or their liver metabolism is clinically insignifi-
Table 1. Generations of antihistamines

\begin{tabular}{ll}
\hline First-generation & $\begin{array}{l}\text { Diphenhydramine, clemastine, } \\
\text { triprolidine, hydroxyzine, } \\
\text { cyproheptadine, promethazine, } \\
\text { antazoline, dimetindene, ketotifen }\end{array}$ \\
\hline Second-generation & $\begin{array}{l}\text { Terfenadine, astemizole - withdrawn } \\
\text { Loratadine, ebastine, cetirizine, } \\
\text { rupatadine, mizolastine, emedastine, } \\
\text { azelastine, bilastine }\end{array}$ \\
\hline Third-generation & $\begin{array}{l}\text { Desloratadine - metabolite of loratadine } \\
\text { Fexofenadine - metabolite } \\
\text { of terfenadine } \\
\text { Levocetirizine - enantiomer of cetirizine }\end{array}$ \\
\hline
\end{tabular}

cant. A simultaneous use of medicines which inhibit the CYP3A4 isoenzyme results in an elevated concentration of these antihistamines in the serum, leading to an increased risk of potential toxic side-effects. Therefore, the use of these antihistamines was not recommended in patients with hepatic disorders or inherited long QT syndrome, similarly to their combined administration with other QT interval prolonging drugs or CYP3A4 isoenzyme inhibitors, including macrolides, itraconazole and ketoconazole [3, 12]. Despite these warnings, new case-studies appeared describing unrecommended combined use of those drugs [13]. Additionally, QT interval prolongation was found in people drinking grapefruit juice combined with other medicines [9]. This might demystify the unexplained arrhythmia cases reported to the Food and Drug Administration (FDA) that had appeared with no apparent predisposing factors. New research suggests that some arrhythmia cases, which were related to terfenadine use, were in fact cases of the life-threatening ventricular tachycardia (other than torsades de pointes), caused by decreased conductivity, due to blocked sodium channels [14]. Astemizole was withdrawn from the market in Europe and the United States in 1997, while terfenadine, which was substituted for its metabolite fexofenadine, was discontinued in 1999 [15].

Due to cardiotoxicity of astemizole and terfenadine, much attention was paid to the safety of other antihistamines. Furthermore, the assessment of novel drugs (bilastine, rupatadine, levocetirizine) was performed in accordance with the precise E14 regulations approved by the ICH (International Conference of Harmonization of Technical Requirements for Registration of Pharma-

Table 2. QT interval measurement

The QT interval measurement is performed from the beginning of the earliest $\mathrm{Q}$ wave (or the $\mathrm{R}$ wave, if the $\mathrm{Q}$ wave is missing) to the end of the $T$ wave, excluding the $U$ wave, if present. A mean result of 3-5 measurements is advisable.

Due to the fact that QT interval is dependent on the heart rate, it is recommended to use correction formulas. The most common is the Bazett's formula, in which the QT interval is divided by the square root of the RR interval (measured before the QT interval). Both intervals must be measured in the same units of time.

The correct value is $430 \mathrm{~ms}$ for adult males, $450 \mathrm{~ms}$ for adult females and $440 \mathrm{~ms}$ for children. Values above $450 \mathrm{~ms}$ in adult males, $470 \mathrm{~ms}$ in adult females and $460 \mathrm{~ms}$ in children are considered as substantially prolonged. 
ceuticals for Human Use). These regulations concern the assessment methods of proarrhythmic potential of non-antiarrhythmic drugs. Some of the most important representatives of antihistamines are noteworthy:

- Diphenhydramine - the proarrhythmic effect, due to the influence on potassium channels, was reported while administering medically overdosed diphenhydramine $[3,16]$. An increased repolarization time and T wave disturbances were also reported in the case of another first-generation antihistamine - hydroxyzine $[3,17,18]$.

- Fexofenadine - this terfenadine metabolite is minimally metabolized. Although a case of prolonged QT interval and ventricular tachycardia while administering fexofenadine had been reported [19], the studies that followed did not confirm its negative effects on QT interval and heart rhythm, neither in high doses nor combined with ketoconazole or erythromycin [20].

- Ebastine - the mechanism of action is based on its active metabolite - carebastine. Although experimental studies did reveal prolonged QT intervals in doses far greater than the ones necessary to block $\mathrm{H} 1$ receptor [21], the clinical studies did not confirm its substantial prolongation in humans. Arrhythmia was not observed, even in patients equipped with a Holter monitor [22-24]. Combined administration of ebastine with ketoconazole or erythromycin resulted in its increased concentration in the serum and a slight QT interval prolongation, yet with no clinical significance whatsoever [23]. Precaution is recommended in the case of patients with prolonged QT interval, hypokalemia and in cases of combined use with QT interval prolonging drugs or isoenzyme CYP3A4 influencing therapeutics [25]. Ebastine is unavailable in Poland.

- Cetirizine - it is excreted in the urine in $70 \%$ and undergoes minute, clinically insignificant metabolism in the liver. Experimental studies $[26,27]$ and human trials did not confirm its effect on potassium channels, nor its properties to induce torsades de pointes [26, 28]. Hekkala et al. [26] assessed the use of cetirizine in patients with inherited type 1 and type 2 long QT syndrome. They did not observe prolonged QT intervals, neither during rest, nor after physical exertion, having administered a therapeutic dose of $10 \mathrm{mg}$ to the patients or $50 \mathrm{mg}$ doses to the healthy volunteers. Levocetirizine in an enantiomer of cetirizine. A study in accordance with $\mathrm{E} 14 \mathrm{ICH}$ regulations did not reveal its effect on repolarization in either therapeutic or higher doses [29].

- Loratadine - is metabolized by CYP3A4 and CYP2D6 isoenzymes, thus interactions with their inhibitors are possible. No substantial influence on the prolongation of QT intervals or ventricular arrhythmia was shown [3, 30]. Taglialatela et al. [27] described a potential experimental possibility of potassium channel blockade and QT prolongation, yet with the use of doses far higher than therapeutic ones. Desloratadine is a metabolite of loratadine. No QT interval prolongation was found as a result of administration of desloratadine [25].

- Mizolastine - is structurally similar to astemizole. When used experimentally, in higher than therapeutic doses, it blocked the potassium channels to some degree [31]. Human trials, however, did not result in QT interval changes, neither with normal doses, nor overdosed [32, 33]. Mizolastine is unavailable in Poland.

- Rupatadine - blocks both $\mathrm{H1}$ and PAF receptors [34]. It binds to potassium channels only in very high concentrations, 400 x higher than the ones achieved with the $20 \mathrm{mg}$ dose [34]. It is metabolized by the CYP3A4 isoenzyme, thus its concentration in the serum is increased during combined use with CYP3A4 inhibitors, yet it has no significant effect on the QT interval prolongation $[35,36]$. Studies on healthy volunteers did not reveal any significant QT prolongation, neither with therapeutic doses, nor while being overdosed 10-fold $[4,36]$. Nonetheless, precaution is recommended in the case of rupatadine use in combination with isoenzyme CYP3A4 inhibitors, in patients with prolonged QT interval, ongoing hypokalemia or in other cases that might result in arrhythmia (such as clinically significant bradycardia or acute myocardial ischemia) [25].

- Bilastine - it is characterized by high selectivity and affinity towards $\mathrm{H} 1$ receptors. It does not show significant activity towards a group of 30 other receptors, including serotonergic, bradykinin, leukotriene, muscarinic, calcium-sensing, $\alpha 1$ and $\beta 2$ adrenergic, as well as $\mathrm{H} 2$ and $\mathrm{H} 3$ receptors [37]. It is excreted unchanged in almost 95\%, it is not metabolized in the liver and does not affect the P450 cytochrome. Due to these advantages, bilastine shows high therapeutic effectiveness with a rapid onset and a long clinical action as well as high reduction of side-effects. A randomized study on 30 healthy volunteers, in accordance with the $\mathrm{E} 14 \mathrm{ICH}$ regulations, revealed that bilastine does not significantly prolong the QT interval and does not cause arrhythmia, when used in therapeutic doses or overdosed 5× [38-41]. Although QT intervals were prolonged in the group of patients that were simultaneously taking bilastine and ketoconazole, this phenomenon was supposedly caused by the anti-fungal drug itself, because the QT prolongation was observed only when ketoconazole reached its maximum concentration [38]. On top of that, these patients showed lowered bilastine concentrations, compared to a group of patients that were overdosed $(100 \mathrm{mg})$ and yet did not experience any prolonged QT intervals. Clinical studies on healthy volunteers revealed that high doses of $10 \times$ to $11 \times$ (220 mg one-time or $200 \mathrm{mg}$ daily for 7 days) did result in a higher incidence of side-effects, yet without any significant QT interval prolongation [38].

The aforementioned studies reveal that the triggering of life-threatening arrhythmia is not a class effect. 
This phenomenon concerns mainly two antihistamines (i.e. terfenadine and astemizole) and is proportional to the level of potassium channel blockade [3]. Therefore, it does not depend on the primary affinity towards $\mathrm{H} 1$ receptors.

Interestingly, Turkish researchers, Erdogan et al., assuming that histamine released from mast cells during acute myocardial infarction causes constriction of coronary vessels, carried out a study, in which loratadine $10 \mathrm{mg}$ daily was added to the standard treatment of acute myocardial infarction [42]. They thought that the antihistamine property of the drug could inhibit the negative effect of histamine in the case of insufficiency of vasodilating factors. They reported better results in cardiac stress tests in patients taking loratadine compared to conventionally treated patients. The hypothesis claiming that mast cells and histamine play a role in acute coronary syndromes attracted more scientific attention. Reid et al. reported that angiotensin II and histamine, which are released by mast cells during heart attack, activate AT1 and histamine $\mathrm{H} 3$ receptors, while the AT1 activation has a proarrhythmic effect and the $\mathrm{H} 3$ activation is cardioprotective [43]. Thus, the researchers suggested that acting upon histamine receptors might create a novel therapeutic option in the future. Furthermore, Matsumori et al. reported a decrease in myocardial necrosis area and lowered levels of inflammatory cytokines and metalloprotease- 2 in mice with viral myocarditis treated with cetirizine [44]. Undoubtedly, the apparent positive effects of antihistamines on the circulatory system require further investigation.

\section{Conclusions}

Effects of potassium channel blockade and QT interval prolongation are not a class effect, but result from the action of only a few antihistamine drugs - arrhythmias with dramatic effects were observed only in the case of the withdrawn therapeutics - terfenadine and astemizole. Such phenomena are potentially manifested only in the cases of high overdose far beyond the suggested therapeutic levels. Furthermore, in the vast majority of these cases the results had no arrhythmogenic consequences. There are certain groups of patients, especially the ones with inherited long QT syndrome, the elderly and patients with cardiovascular diseases, who require special attention, once they are to be treated with any of the vast majority of antihistamines. In such cases, patients should be warned not to overdose their prescribed antihistamines and not to combine them with CYP3A4 inhibitors (e.g. anti-fungal drugs and macrolides), nor with any drugs prolonging QT intervals. The optimal way to avoid these problems is to use antihistamines with the highest level of cardiovascular safety, e.g. bilastine, which does not affect the CYP3A4 isoenzyme, nor the QT interval, even when overdosed.

\section{Conflict of interest}

Anna Olasińska-Wiśniewska - lecture honorarium from Berlin-Chemie.

\section{References}

1. Grzelewska-Rzymowska I, Górski P. Rupatadine: a novel second-generation antihistamine. Postep Derm Alergol 2011; 20: 489-97.

2. O'Byrne P, Persson C, Church M. Cellular and mediator mechanisms of the early stage of immunological response. In: Allergy [Polish]. Holgate ST, Church MK, Lichtenstein LM (eds.). Czelej, Lublin, Poland 2004; 325-7.

3. Szewczyk J, Kruszewski J. The influence of antihistamines on the cardiovascular system. Alergia Astma Immunologia 2001; 6: 135-41.

4. Lukat K, Rivas P, Roger A, et al. A direct comparison of efficacy between desloratadine and rupatadine in seasonal allergic rhinoconjunctivitis: a randomized, double-blind, placebo-controlled study. J Asthma Allergy 2013; 6: 31-9.

5. Taglialatela M, Annunziato L. Evaluation of the cardiac safety of second-generation antihistamines. Allergy 2000; 55 Suppl. 60: 22-30.

6. Dávila I, Sastre J, Bartra J, et al. Effect of $\mathrm{H} 1$ antihistamines upon the cardiovascular system. J Investig Allergol Clin Immunol 2006; 16 Suppl. 1: 13-23.

7. Craft TM. Torsade de pointes after astemizole overdose. $\mathrm{Br}$ Med J (Clin Res Ed) 1986; 292: 660.

8. Davies AJ, Harindra V, McEwan A, Ghose RR. Cardiotoxic effect with convulsions in terfenadine overdose. BMJ 1989; 298: 325 .

9. Woosley RL. Cardiac actions of antihistamines. Annu Rev Pharmacol Toxicol 1996; 36: 233-52.

10. Bishop RO, Gaudry PL. Prolonged Q-T interval following astemizole overdose. Arch Emerg Med 1989; 6: 63-5.

11. Monahan BP, Ferguson CL, Killeavy ES, et al. Torsades de pointes occurring in association with terfenadine use. JAMA 1990; 264: 2788-90.

12. Woosley RL, Chen Y, Freiman JP, Gillis RA. Mechanism of the cardiotoxic actions of terfenadine. JAMA 1993; 269: 1532-6.

13. Zechnich AD, Hedges JR, Eiselt-Proteau D, Haxby D. Possible interactions with terfenadine or astemizole. West J Med 1994; 160: 321-5.

14. Lu HR, Hermans AN, Gallacher DJ. Does terfenadine-induced ventricular tachycardia/fibrillation directly relate to its QT prolongation and Torsades de Pointes? Br J Pharmacol 2012; 166: 1490-502.

15. Gottlieb S. Antihistamine drug withdrawn by manufacturer. BMJ 1999; 319: 7.

16. Husain Z, Hussain K, Nair R, Steinman R. Diphenhydramine induced QT prolongation and torsade de pointes: an uncommon effect of a common drug. Cardiol J 2010; 17: 509-11.

17. Lee BH, Lee SH, Chu D, et al. Effects of the histamine $H(1)$ receptor antagonist hydroxyzine on hERG $\mathrm{K}(+)$ channels and cardiac action potential duration. Acta Pharmacol Sin 2011; 32: 1128-37.

18. Hollister LE. Hydroxyzine hydrochloride: possible adverse cardiac interactions. Psychopharmacol Commun 1975; 1: 61-5.

19. Pinto YM, van Gelder IC, Heeringa M, Crijns HJ. QT lengthening and life-threatening arrhythmias associated with fexofenadine. Lancet 1999; 353: 980.

20. Pratt C, Brown AM, Rampe D, et al. Cardiovascular safety of fexofenadine HCl. Clin Exp Allergy 1999; 29 Suppl. 3: 212-6. 
21. Hey JA, del Prado M, Kreutner W, Egan RW. Cardiotoxic and drug interaction profile of the second generation antihistamines ebastine and terfenadine in an experimental animal model of torsade de pointes. Arzneimittelforschung 1996; 46: 159-63.

22. Gillen MS, Miller B, Chaikin P, Morganroth J. Effects of supratherapeutic doses of ebastine and terfenadine on the QT interval. Br J Clin Pharmacol 2001; 52: 201-4.

23. Moss AJ, Chaikin P, Garcia JD, et al. A review of the cardiac systemic side-effects of antihistamines: ebastine. Clin Exp Allergy 1999; 29 Suppl. 3: 200-5.

24. Hurst M, Spencer CM. Ebastine: an update of its use in allergic disorders. Drugs 2000; 59: 981-1006.

25. Dávila I, del Cuvillo A, Mullol J, et al. Use of second generation $\mathrm{H} 1$ antihistamines in special situations. J Investig Allergol Clin Immunol 2013; 23 Suppl. 1: 1-16.

26. Hekkala AM, Swan H, Väänänen $H$, et al. The effect of antihistamine cetirizine on ventricular repolarization in congenital long QT syndrome. J Cardiovasc Electrophysiol 2007; 18: 691-5.

27. Taglialatela M, Pannaccione A, Castaldo P, et al. Molecular basis for the lack of HERG K+ channel block-related cardiotoxicity by the $\mathrm{H} 1$ receptor blocker cetirizine compared with other second-generation antihistamines. Mol Pharmacol 1998; 54: 113-21.

28. Sale ME, Barbey JT, Woosley RL, el al. The electrocardiographic effects of cetirizine in normal subjects. Clin Pharmacol Ther 1994; 56: 295-301.

29. Hulhoven R1, Rosillon D, Letiexhe M, et al. Levocetirizine does not prolong the QT/QTc interval in healthy subjects: results from a thorough QT study. Eur J Clin Pharmacol 2007; 63: 1011-7.

30. Hey JA, Del Prado M, Cuss FM, et al. Antihistamine activity, central nervous system and cardiovascular profiles of histamine $\mathrm{H} 1$ antagonists: comparative studies with loratadine, terfenadine and sedating antihistamines in guinea-pigs. Clin Exp Allergy 1995; 25: 974-84.

31. Taglialatela M, Pannaccione A, Castaldo P, et al. Inhibition of HERG1 $\mathrm{K}(+)$ channels by the novel second-generation antihistamine mizolastine. Br J Pharmacol 2000; 131: 1081-8.

32. Chaufour S, Caplain H, Lilienthal N, et al. Study of cardiac repolarization in healthy volunteers performed with mizolastine, a new H1-receptor antagonist. Br J Clin Pharmacol 1999; 47: 515-20.

33. Delauche-Cavallier MC, Chaufour S, Guérault E, et al. QT interval monitoring during clinical studies with mizolastine, a new $\mathrm{H1}$ antihistamine. Clin Exp Allergy 1999; 29 Suppl. 3: 206-11.

34. Caballero R, Valenzuela C, Longobardo M, et al. Effects of rupatadine, a new dual antagonist of histamine and platelet-activating factor receptors, on human cardiac kv1.5 channels. Br J Pharmacol 1999; 128: 1071-81.

35. Izquierdo I, Merlos M, García-Rafanell J. Rupatadine: a new selective histamine $\mathrm{H} 1$ receptor and platelet-activating factor (PAF) antagonist. A review of pharmacological profile and clinical management of allergic rhinitis. Drugs Today (Barc) 2003; 39: 451-68.

36. Donado E, Izquierdo I, Pérez I, et al. No cardiac effects of therapeutic and supratherapeutic doses of rupatadine: results from a 'thorough QT/QTc study' performed according to ICH guidelines. Br J Clin Pharmacol 2010; 69: 401-10.

37. Corcóstegui R1, Labeaga L, Innerárity A, et al. Preclinical pharmacology of bilastine, a new selective histamine $\mathrm{H} 1$ receptor antagonist: receptor selectivity and in vitro antihistaminic activity. Drugs R D 2005; 6: 371-84.

38. Tyl B, Kabbaj M, Azzam S, et al. Lack of significant effect of bilastine administered at therapeutic and supratherapeutic doses and concomitantly with ketoconazole on ventricular repolarization: results of a thorough QT study (TQTS) with QT-concentration analysis. J Clin Pharmacol 2012; 52: 893-903.

39. Graff C, Struijk JJ, Kanters JK, et al. Effects of bilastine on T-wave morphology and the QTc interval: a randomized, double-blind, placebo-controlled, thorough QTc study. Clin Drug Investig 2012; 32: 339-51.

40. Lasseter KC, Sologuren A, La Noce A, Dilzer SC. Evaluation of the single-dose pharmacokinetics of bilastine in subjects with various degrees of renal insufficiency. Clin Drug Investig 2013; 33: 665-73.

41. Zuberbier T, Oanta A, Bogacka E, et al. Bilastine International Working Group. Comparison of the efficacy and safety of bilastine $20 \mathrm{mg}$ vs levocetirizine $5 \mathrm{mg}$ for the treatment of chronic idiopathic urticaria: a multi-centre, double-blind, randomized, placebo-controlled study. Allergy 2010; 65: 516-28.

42. Erdogan O, Altun A, Gazi S, Ozbay G. Loratidine improves ischemic parameters of exercise stress test in patients with acute myocardial infarction. Am Heart J 2004; 148: e24.

43. Reid AC, Brazin JA, Morrey C, et al. Targeting cardiac mast cells: pharmacological modulation of the local renin-angiotensin system. Curr Pharm Des 2011; 17: 3744-52.

44. Matsumori A, Yamamoto K, Shimada M. Cetirizine a histamine $\mathrm{H} 1$ receptor antagonist improves viral myocarditis. J Inflamm (Lond) 2010; 7: 39. 